\title{
Frontières
}

\section{Nouvelles parutions - Études sur la mort}

\section{Ngoc-Thanh Phan Nguyen}

Volume 20, numéro 2, printemps 2008

Les musiques et la mort

URI : https://id.erudit.org/iderudit/018369ar

DOI : https://doi.org/10.7202/018369ar

Aller au sommaire du numéro

Éditeur(s)

Université du Québec à Montréal

ISSN

1180-3479 (imprimé)

1916-0976 (numérique)

Découvrir la revue

Citer ce document

Phan Nguyen, N.-T. (2008). Nouvelles parutions - Études sur la mort. Frontières, 20(2), 122-122. https://doi.org/10.7202/018369ar d'utilisation que vous pouvez consulter en ligne.

https://apropos.erudit.org/fr/usagers/politique-dutilisation/ 


\section{NOUVELLES PARUTIONS-} ÉTUDES SUR LA MORT

Ngoc-Thanh Phan Nguyen, bibliothécaire de référence, Bibliothèque centrale, UQAM.

ANDRY, Kimberly (2007). A Time to Live: Surviving Suicidal Thoughts, Parker (Colorado), Outskirts Press.

AUTHIER-ROUX, Frédérique (2007). Ces bébés passés sous silence: à propos des interruptions médicales de grossesse, Ramonville-Saint-Agne (Haute-Garonne), Erès, coll. "Mille et un bébés. Avant la naissance».

BACQUÉ, Marie-Frédérique (2008). L'un sans I'autre: psychologie du deuil et des séparations, Paris, Larousse, coll. "L'univers psychologique».

BADINTER, Robert (2007). L'abolition de la peine de mort, Paris, Dalloz, coll. «À savoir».

BASSET, Lytta (2007). Ce lien qui ne meurt jamais, Paris, Albin Michel, coll. «Documents».

BAYARD, Jean-Pierre (2007). Le sens caché des rites mortuaires, Escalquens (Haute-Garonne)، Dangles, coll. «Horizons ésotériques".

CAMPBELL, Margaret L. (2008). Nurse to Nurse: Palliative Care, New York, McGraw-Hill.

CLERGET, Stéphane (2008). Quel âge aurait-il aujourd'hui ?: le tabou des grossesses interrompues, Paris, Fayard.

DASTUR, Françoise (2007). La mort: essai sur la finitude, Paris, Presses universitaires de France, coll. «Epiméthée».

DEREGNAUCOURT, Jean-Pierre (2007). La mort au Moyen Âge: les hommes et la mort à la fin du Moyen Âge, Paris, J.-P. Gisserot, coll. "Gisserot Histoire ».

FAHERTY, Catherine (2008). Understanding Death and IIIness and What They Teach about Life: A Practical Guidebook for People with Autism or Aspergers, and Their Loved Ones, Arlington (Texas), Future Horizons.

FALCON, Georgina (2007). Les naufrages du cœur: de la survie à la vie, Montréal, Mediaspaul, coll. "Vivre plus».

GREEN, André (2007). Narcissisme de vie, narcissisme de mort, Paris, Minuit, coll. "Rerprise», no 14.

GREEN, James W. (2008). Beyond the Good Death: The Anthropology of Modern Dying, Philadelphie (PA), University of Pennsylvania Press.

HANUS, Michel et al. (2007). Le grand livre de la mort à l'usage des vivants, Paris, Albin Michel.

HÉRACLÈS, Philippe (2007). 100 bonnes raisons d'être mort, Paris, le Cherche Midi, coll. "Le sens de l'humour".

HERRING, Jonathan (dir.) (2008). Death Rites and Rights, Oxford (Angleterre), Hart Publishing.

ISRÄEL, Lucien (2007). Pulsions de mort: deux séminaires, 1977 et 1978, Ramonville-Saint-Agne (Haute-Garonne) Erès; Strasbourg, Arcanes, coll. «Hypothèses ».
JOINER, Thomas (2007). Why People Die by Suicide, Cambridge (Mass.), Harvard University Press.

LAAGE BLANC-GARIN, Monique et BLANCGARIN, Jacques (2008). En communion avec nos défunts: dans l'infinitude de l'amour, Monaco, Alphée-Jean-Paul Bertrand, coll. "Documents».

LAFON, Claude (2007).Vieillissement et longévité, Paris, Ellipses, coll. "L'esprit des sciences ».

LARIN, Judith (2007). Accompagner la vie, Montréal, Alain Stanké.

LÉGER, Pierre (2008). La mort et l'au-delà, Montréal, Novalis, coll. " 25 questions».

LEONG, Frederick T. L. (dir.) (2007). Suicide Among Racial and Ethnic Groups: Theory, Research, and Practice, Londres, Routledge.

MCLAUGHLIN, Columba (2007). Suicide-Related Behaviour: Understanding, Caring and Therapeutic Responses, New York, Wiley.

MICHAUD NÉRARD, François (2007). La révolution de la mort, Paris, Vuibert, coll. "Espace éthique».

MITCHELL, John B. (2008). Understanding Assisted Suicide: Nine Issues to Consider, Ann Arbor, University of Michigan Press.

MYTTENAERE, Chantal (2007). Panser le deuil, Grolley (Suisse), L'Hèbe, coll. «Paradigmes ».

OSBORNE, Millie (2007). The Inner World of a Suicidal Youth: What Every Parent and Health Professional Should Know, Westport (CT), Praeger.

PALMER, Stephen (2007). Strategies and interventions to reduce or prevent suicide, Londres, Routledge.

PARLER DE LA MORT (2008). Paris, sous presse, coll. "Libres cahiers pour la psychanalyse, $\mathrm{n}^{\circ} 11$ ".

PIERRE, Abbé (2007). La consolation des consolations: l'abbé Pierre parle de la mort, Paris, Presses du Châtelet.

PIGAILLEM, Henri (2008). Petit dico insolite de la mort: morts célèbres et absurdes, anecdotes et chroniques, Grainville (Eure), City.

SEWANE, Dominique (2007). Le souffle du mort: la tragédie de la mort chez les Batammariba du Togo, Bénin, Paris, Pocket.

SOUBIEUX, Marie-José (2008). Le berceau vide: deuil périnatal et travail du psychanalyste, Ramonville-Saint-Agne (Haute-Garonne), Erès, coll. "La vie de l'enfant».

TATARELLI, Roberto (dir.) (2008). Suicide in Psychiatric Disorders, Hauppauge (N.Y.), Nova Science Publishers.

VALENTINE, Chris (2008). Bereavement in Contemporary Society, Londres, Routledge.

ZITTOUN, Robert (2007). La mort de l'autre: une introduction à l'éthique clinique, Paris, Dunod, coll. «Action sociale». 